\title{
Seasonal occurrence of Plutella xylostella (Lepidoptera: Yponomeutidae) on Ishigaki-jima Island, with special reference to their sudden occurrence associated with a typhoon
}

\author{
Katsuyuki Kohno, ${ }^{1, *}$ Hiroshi SoEMorI ${ }^{2}$ and Keiichi TAKAHASHI ${ }^{1, \dagger}$ \\ ${ }^{1}$ Okinawa Subtropical Station, Japan International Research Center for Agricultural Sciences; Maezato, Ishigaki, Okinawa \\ 907-0002, Japan \\ ${ }^{2}$ Yaeyama Branch, Okinawa Prefectural Agricultural Experiment Station; Hirae, Ishigaki, Okinawa 907-0003, Japan \\ (Received 9 May 2003; Accepted 14 October 2003)
}

\begin{abstract}
Seasonal occurrences of the diamond-back moth (DBM), Plutella xylostella were investigated on Ishigaki-jima Island, the southernmost part of the Southwest Islands of Japan. The number of DBM captured on Ishigaki-jima Island was relatively high from October to the subsequent May every year in the presence of a sufficient amount of cabbages; however, the number was very low or zero during summer, probably because the host plant was scarce and/or the air temperature was too high. Just after the passing of a typhoon near Ishigaki-jima Island in October 1998, sudden trap catches of DBM were observed, which is assumed to be based on immigration via air currents associated with the typhoon. Since many temperate exotic butterflies were collected on and near Ishigaki-jima Island at the same period, the sudden increase of the trap catch of DBM at that time is assumed to indicate that these DBM have the same regional origin as those butterflies, which was assumed to be central China or more northern areas. The impact of the migration of DBM associated with the typhoon on their population increase on Ishigaki-jima Island, however, did not appear to be significant.
\end{abstract}

Key words: Plutella xylostella; migration; typhoon; seasonal occurrence; subtropical island

\section{INTRODUCTION}

The diamond-back moth (DBM), Plutella $x y$ lostella (Linnaeus) (Lepidoptera: Yponomeutidae) is one of the most serious insect pests of cruciferous crops throughout the world (e.g., Shaw, 1960). Though most cruciferous crops are grown in temperate zones (Fujieda, 1993), the cultivation of cruciferous crops is somewhat common on Ishigakijima Island, which is located in the southernmost part of the Southwest Islands of Japan (ca. $24^{\circ} \mathrm{N}$ and $124^{\circ} \mathrm{E}$ ) whose climate is subtropical monsoon and somewhat maritime. The cultivation period of cruciferous crops is limited from autumn to the subsequent spring, since the weather in summer is too hot (mean air temperature from June to September is above $27^{\circ} \mathrm{C}$ ) for their cultivation. In addition to cultivated cruciferous plants, some wild cruciferous plants are distributed in this area (Hatusima, 1975; Walker, 1976); however, such wild cruciferous plants are rarely found on Ishigaki-jima
Island during summer. Therefore, it is assumed to be very difficult for DBM to maintain a continuous presence on Ishigaki-jima Island because of host plant deficiency or the high temperature range during summer. However, DBM occurs every year on Ishigaki-jima Island (H. Soemori, unpublished), suggesting that annual immigration from other areas occurs.

DBM is well known also as a long-distance migrant insect (e.g., Shaw and Hurst, 1969). For example, the sudden outbreak of DBM in Britain in 1958 is assumed to have been based on the mass immigration from the European continent via air currents associated with a front (French and White, 1960; Shaw, 1962). Moreover, DBM occurrence in Spitsbergen, which is located within the Arctic Circle, is assumed to be possible through the air currents associated with a depression (Lokki et al., 1978). Therefore the immigration of DBM onto Ishigaki-jima Island is assumed to occur in some part due to the air currents of a monsoon or a front.

\footnotetext{
* To whom correspondenc should be addressed at: E-mail: kohno@affrc.go.jp

$\dagger$ Present address: 1306-23 Shimone-machi, Ushiku, Ibaraki 300-1203, Japan
} 
In addition, Miyahara (1986) observed irregular mass trap catches of DBM that were presumed to be caused by the movement of a front associated with a typhoon in northern Japan. However, there has been no observation of the immigration of DBM associated with a typhoon in the Southwest Islands of Japan including Ishigaki-jima Island, although this area suffers the effect of typhoons every year.

Thus we began to investigate the seasonal trends of the occurrence of DBM on Ishigaki-jima Island in order to identify the meteorological causes of the abundance of DBM there. During the investigation, we observed a sudden occurrence of DBM just after the passing of a typhoon near Ishigakijima Island. In this report, we describe the features of the seasonal trends of the occurrence of DBM and discuss the association between the sudden DBM occurrence and the typhoon. In addition, we consider the regional origin of the DBM that occurred just after the passing of the typhoon, with reference to the occurrence of some exotic butterflies on and near Ishigaki-jima Island during the same period.

\section{MATERIALS AND METHODS}

The population fluctuation of the adult DBM was determined in terms of the number of catches at sticky traps ("SE trap Type S" produced by Sankei Chemical Co. Ltd.) using a sex pheromone lure ("PX" produced by Takeda Chemical Industries Ltd.) at the upland fields of the Okinawa Subtropical Station, Japan International Research Center for Agricultural Sciences (JIRCAS) $\left(24^{\circ} 23^{\prime} \mathrm{N}\right.$, $\left.124^{\circ} 12^{\prime} \mathrm{E}\right)$ on Ishigaki-jima Island. One trap was situated near a cabbage field, and another was situated $300 \mathrm{~m}$ away from that field on July 31, 1997. Each trap was examined twice a month from $\mathrm{Au}-$ gust 1997 to August 2001 to count the trapped DBM. The sex pheromone lure was replaced once a month. The traps were tentatively removed during the period from 13:00 October 15, 1998 to 17:00 October 17, 1998 in order to avoid typhoon damage.

The area of the cabbage field for the experiment was about $2,000 \mathrm{~m}^{2}$. In the cabbage field, about 200 seedlings (variety "Sôshû" bred by Takii Seed Co. Ltd., which exhibits relatively high heat tolerance) were planted at one time in a $200 \mathrm{~m}^{2}$ area at about one month intervals from September 1997 to December 1999. Polyethylene net (approximately $0.6 \mathrm{~mm}$ mesh) was applied as row cover material for approximately one month after planting in the field in order to prevent early infection by insect pests (Morishita and Azuma, 1990; Makino and Kawai, 2000). The purpose of this design is to maintain enough cabbage in the field all year 'round throughout the duration of the experiment. All the cabbages planted in the field were removed on April 18, 2000. After that, no cruciferous crops were planted near either trap until the end of the experiment at the beginning of August 2001. Cruciferous crops were cultivated outside the station from autumn to the subsequent spring every year. The nearest cruciferous crop field was about $400 \mathrm{~m}$ away from the observed area.

Meteorological data were obtained in the field around the station and from the literature. The occurrence of extraordinary weather conditions such as typhoons was recorded. The extra occurrence of exotic butterflies in this area has also been observed in the field on Ishigaki-jima Island, and investigated in the literature.

\section{RESULTS}

Although we intended to maintain a sufficient amount of cabbage in the field all year 'round, the amount of cabbage apparently became scarce at times because of outbreaks of insect pests other than DBM, such as Artogeia rapae crucivora (Boisduval) (April to June 1998), Spodoptera litura (Fabricius) (June to July 1998), and Crocidolomia binotalis Zeller (June to July 1999), and probably because of the hot weather from July to September of every year (Fig. 1).

The trap catches of DBM near the cabbage field began to increase in October and ceased in the subsequent May every year within the period from middle August 1997 to middle April 2000, when the cabbages were cultivated in the field (Fig. 1). The peak level of the trap catches near the cabbage field each winter within that period was relatively high in 1997-1998 and 1998-1999 and relatively low in 1999-2000. The trap catches of DBM during the summer months were zero or very few every year, perhaps because the amount of cabbage in the field was insufficient to attract DBM. On the other hand, the trap catches of DBM $300 \mathrm{~m}$ distant 

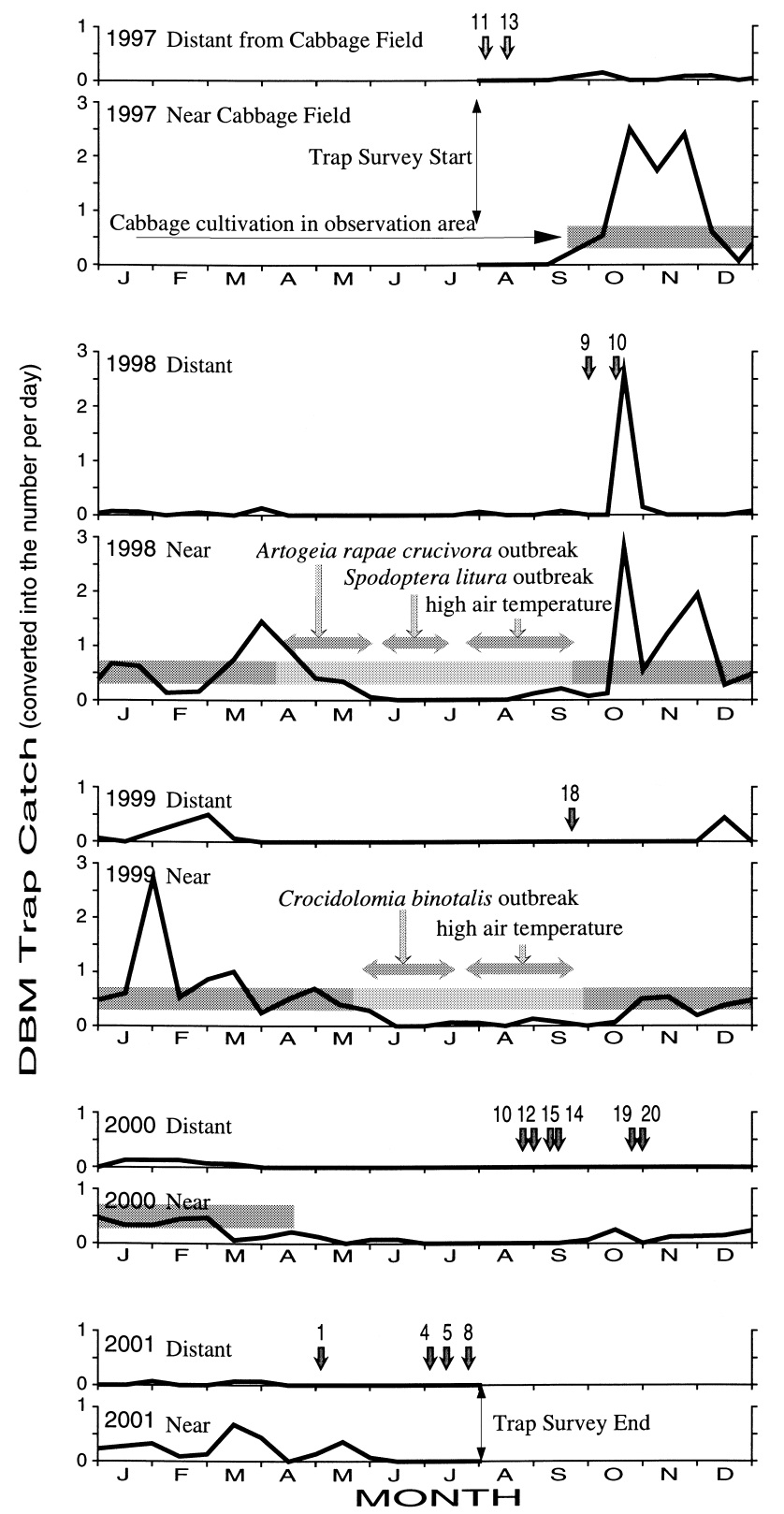

Fig. 1. Seasonal changes in the sex pheromone-lure trap catches of the diamondback moth (DBM), Plutella xylostella L. Values are represented by mean catches per day. Arrows accompanied by a number indicate the passing of typhoons; the number indicates the serial No. of the typhoon of the respective year. Horizontal shaded bands indicate the cabbage cultivation period in the observation area; the sparsely shaded area of the band indicates the period when the amount of cabbages are few, and the causes are added with arrows.

from the cabbage field were almost zero during summer and very few even during the period from October to the subsequent May, with only one exception in October 1998, which is described below.

The occurrence of the typhoon that caused sig-

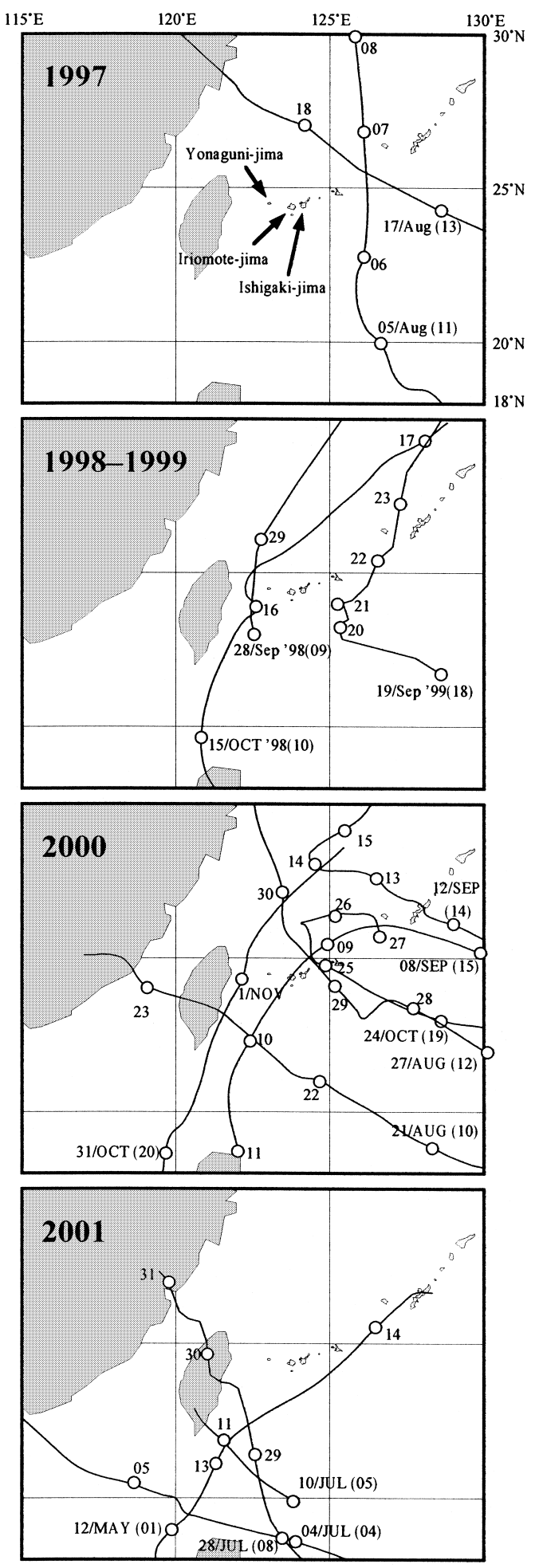

Fig. 2. Tracks of typhoons that affected Ishigaki-jima and neighboring islands from 1997 to 2001. The typhoons' tracks were drawn based on information appearing in Okinawa Meteorological Station reports (1998-2002). Open circles accompanied by a number indicate the position of typhoons at 0900 JST of respective day. Numbers in parentheses are the number of typhoons during the respective years. 
nificant effects in this area is also shown in Fig. 1, and the tracks of typhoons near the study area are shown in Fig. 2. A conspicuous DBM trap catch increase at both traps was observed at almost the same period as the passing of the typhoon No. 10 of 1998 among these fifteen typhoons. The typhoon passed northward between Taiwan and Yonaguni-jima Islands, and then turned to northeastward (Miyahira, 1999; Okinawa Meteorological Station, 1999). For about one day just after the passing of the typhoon, a strong northwestward wind was observed on Ishigaki-jima Island. During the same period, many irregular occurrences of butterflies were recorded at and near Ishigaki-jima Island (Table 1). All the species listed in Table 1 are regarded as exotic species in this area and have their origins in the temperate zone. The collection records of the species listed in Table 1 throughout the experiment period are shown in Table 2.

\section{DISCUSSION}

The trap catches of DBM near the cabbage field were relatively high from autumn to the subsequent spring each year (Fig. 1). This seemed to coincide with the changes in the amount of cabbage in the observed area and the cultivation period of cruciferous crops in this area. Since the trap catches of DBM distant from the observed area were usually small during the same period, the trap catch of DBM near the observed area should have significantly reflected the number or density of the DBM in the observed area, although a direct census in the observed area was not performed.

Since we could not successfully cultivate cabbages during summer, it is difficult to conclude

Table 1. Collection records regarding temperate exotic butterfly species in autumn 1998 in the Yaeyama area, the most southwestern part of the Southwest Islands of Japan

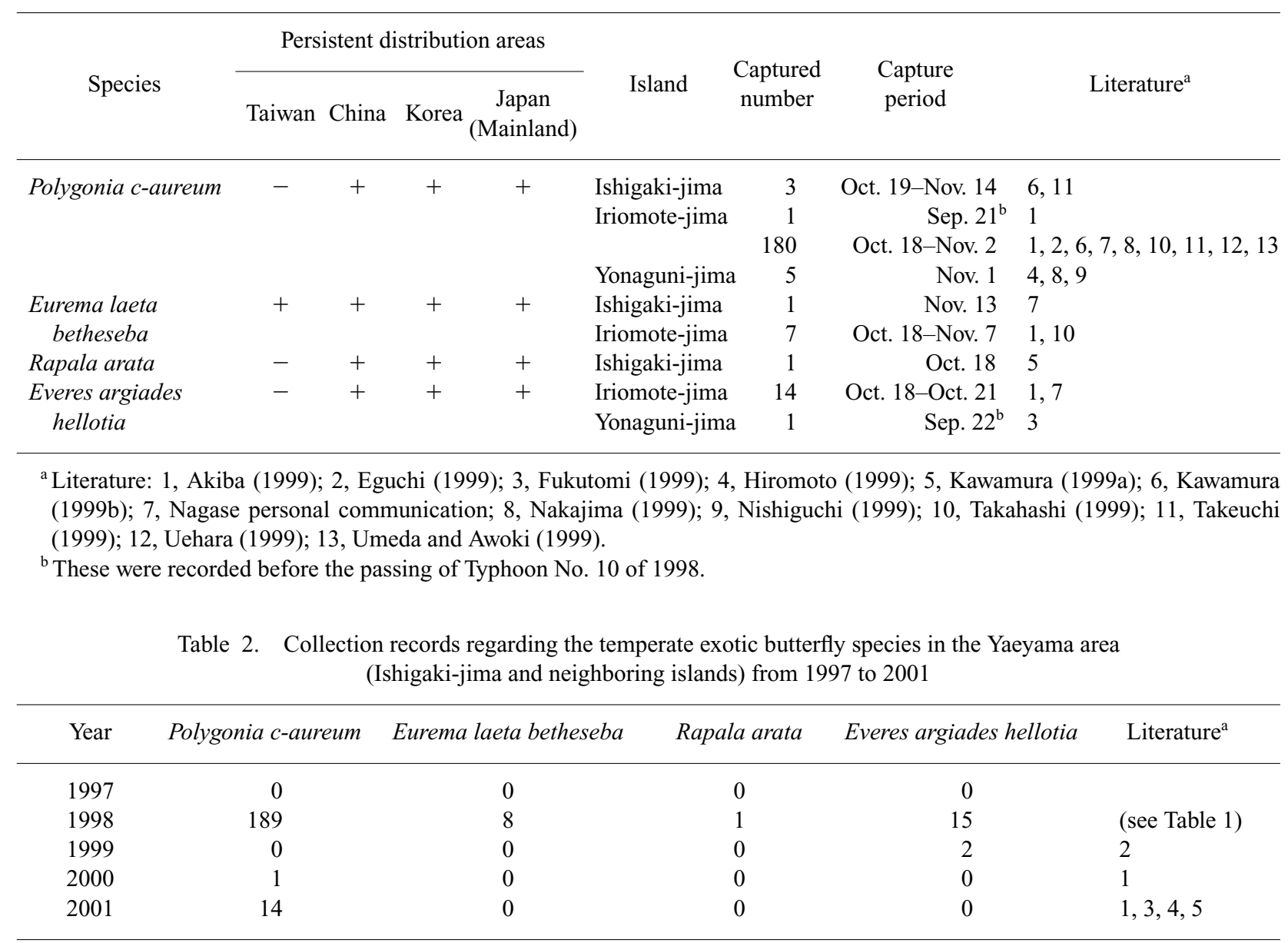

\footnotetext{
${ }^{\text {a }}$ Literature: 1, Kohno unpublished; 2, Mitarai (2000); 3, Nakanishi (2002); 4, Takegami (2002); 5, Yamada (2002).
} 
whether the cause of the population decrease of DBM in the summer months is due to hot weather. However, the trends of the population fluctuation exhibited by the trap catch near a cabbage field may represent the typical features of the island, since the commercial cultivation of cruciferous crops on the island is almost non-existent during summer. The occurrence of the small white butterfly, $A$. rapae crucivora, which feeds on the same cruciferous crops as DBM, on Okinawa Island in the Southwest Islands exhibits seasonal trends very similar to those of DBM on Ishigaki-jima Island. The cause of the population decrease of $A$. rapae crucivora on Okinawa Island in summer was explained by the increased mortality during the egg, larval, and pupal stages and the deficiency of host plants (Itô et al., 1975), although the causes of the mortalities themselves are almost unknown. Since the host plant species and seasonal trends in the occurrence of both species on each island are very similar to each other, the increase of mortality might have affected the summer decrease of DBM on Ishigaki-jima Island. However, this hypothesis should be examined by more precise observations in the field.

At any rate, we can conclude that the population size of DBM on Ishigaki-jima Island during summer is very small. Therefore, the sudden increase of the DBM trap catch at both traps just after the passing of a typhoon in October, 1998, could be considered a result of immigration via air currents associated with the typhoon rather than a result of the population increase of DBM within the island. The recorded collection of many exotic butterflies in the same area at the same period (Table 1) could also be due to immigration via air currents associated with the typhoon. Among the four temperate exotic butterfly species listed in Table 1, three species except for Eurema laeta betheseba (Janson) are not distributed in Taiwan. Therefore it should be regarded that these exotic butterflies collected in the area during that period have their regional origin in central China or more northern areas. Since the sudden increase of the DBM trap catches were observed at the same period of the collection of these exotic butterflies in the same area, it is highly probable that the trapped DBM have the same regional origin as the four exotic butterfly species listed in Table 1 .

Besides Typhoon No. 10 of 1998, many ty-

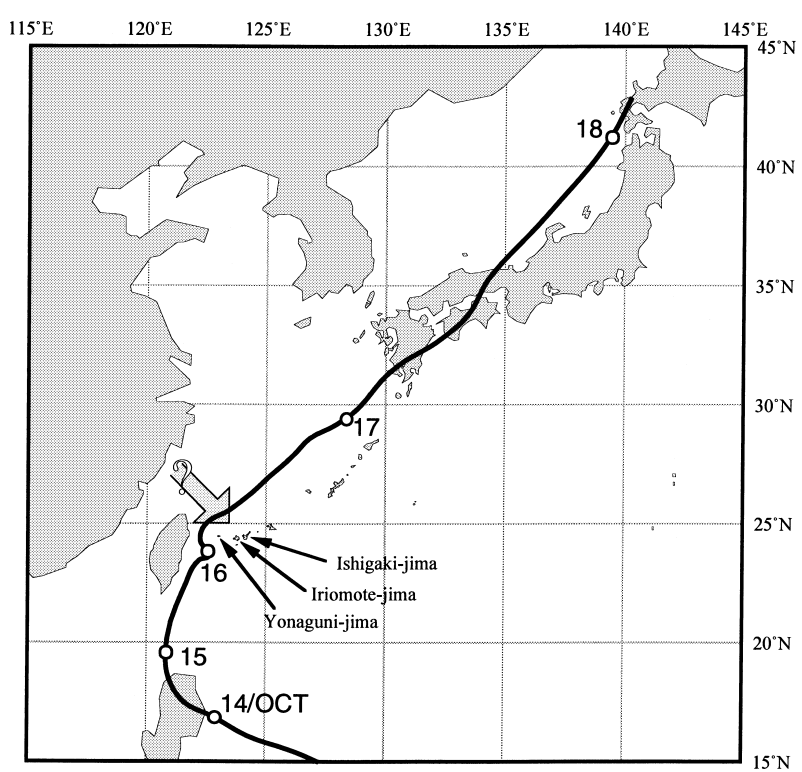

Fig. 3. The track of Typhoon No. 10 of 1998 (Line with open circles) and supposed migration route of the diamondback moth, Plutella xylostella L. and temperate exotic butterflies to Ishigaki-jima Island (Arrow with question mark). The track of the typhoon was drawn based on the information appearing in an Okinawa Meteorological Station report (1999). Open circles accompanied by a number indicate the position of the typhoon at $0900 \mathrm{JST}$ of the respective day.

phoons passed near the study area during the study period (Fig. 2); however, a prominent occurrence of DBM and/or temperate exotic butterflies accompanied by typhoons was not observed (Fig. 1, Table 2). This may indicate that typhoons other than No. 10 of 1998 did not cause air currents sufficient for carrying the above-mentioned insects from their original habitat to Ishigaki-jima and neighboring islands. The track of Typhoon No. 10 of 1998 apparently provoked air currents from China to Ishigaki-jima Island just after the typhoon's passing (Fig. 3). The tracks of Typhoon No. 9 of 1998 and No. 20 of 2000 were similar to that of Typhoon No. 10 of 1998; however, the energy of the former two typhoons was apparently smaller than that of the latter, which may be one of the reasons why those typhoons did not produce any air currents carrying DBM and/or exotic butterflies. Judging from their tracks, all the typhoons except for the above-mentioned three apparently did not produce any air currents from China or Taiwan just after passing near the study area.

In October 1998, a mass immigration of DBM associated with a typhoon should surely have oc- 
curred on Ishigaki-jima Island; however, the occurrence of DBM in the observed area thereafter was not significantly abundant when compared with that of other years. Unrelated to a mass immigration, the populations of DBM during winter were somewhat high every year. Therefore, the immigration of DBM other than that associated with a typhoon should have more influence on its establishment on the island. This is in contrast with the case of $S$. litura. Murata et al. (1998) pointed out that the population increase of $S$. litura in the southwestern Japanese mainland is clearly affected by air currents associated with typhoons.

The seasonal trends of the occurrence of DBM on the island can be explained partly by immigration; however, the possibility of DBM's survival under the deficiency of the host plant and during hot weather during summer should be considered when attempting to determine the complete life history of DBM on the island.

\section{ACKNOWLEDGEMENTS}

We thank Yoichi Shirai (National Institute for Agro-Environmental Sciences) for providing information regarding DBM, Tomonari Watanabe (National Agricultural Research Center) for providing the information regarding the migration of insects associated with meteorological factors, Masayoshi Nagase (Nagoya Plant Protection Station) for providing unpublished collection data regarding exotic butterflies in the Yaeyama area, and Kiyoshi Ozawa (Okinawa Subtropical Station, JIRCAS) for offering information regarding row cover materials.

\section{REFERENCES}

Akiba, K. (1999) Collection records of immigrant butterflies on Iriomote-jima Island in 1998. Chôken Field 14 (7): 21-22 (in Japanese).

Eguchi, E. (1999) Immigrated butterflies collected on the South West Islands in 1997 and 1998. Chôken Field 14 (10): 26 (in Japanese).

French, R. A. and J. H. White (1960) The diamond-back moth outbreak of 1958. Plant Pathology 9: 77-84.

Fujieda, K. (1993) Yasai no Kigen to Bunka (The Origin and the Differentiation of Vegetables). Kyushu University Press, Fukuoka. 165 pp. (in Japanese).

Fukuotomi, H. (1999) Everes argiades hellotia was collected on Yonaguni-jima Island. Chôken Field 14 (1): 18 (in Japanese).

Hatusima, S. (1975) Flora of the Ryukyus (including Amami Islands, Okinawa Islands, and Sakishima Archipelago) (Added and Corrected). Okinawa Society of Education for Biology, Naha. 1,002 pp. (in Japanese).

Hiromoto, K. (1999) Butterflies collected on Yaeyama Islands. Chôken Field 14 (7): 22 (in Japanese).

Itô, Y., M. Sakiyama and M. Osada (1975) Population dy- namics of Pieris rapae crucivora Boisduval (Lepidoptera: Pieridae), an introduced insect pest in Okinawa. II. Features of the population dynamics based on the results of one-year survey. Jpn. J. Appl. Entomol. Zool. 19: 29-34 (in Japanese with English summary).

Kawamura, A. (1999a) Rapala arata was collected on Ishigaki-jima Island. Chôken Field 14 (1): 18 (in Japanese).

Kawamura, A. (1999b) Collection records of immigrant butterflies including Phalanta phalantha. Chôken Field 14 (2): 25-26 (in Japanese).

Lokki, J., K. K. Malmström and E. Suomalainen (1978) Migration of Vanessa cardui and Pulutella xylostella (Lepidoptera) to Spitsbergen in the summer 1978. Notulae Entomologicae 58: 121-123.

Makino, T. and S. Kawai (2000) Establishment of year-round culture system for Brassica in Miyakojima, OkinawaAvoidance of damage by pests to Komatsuna-. Jpn. J. Trop. Agr. 44 (ex. 2): 73-74 (in Japanese).

Mitarai, Y. (2000) Butterflies collected in Yaeyama. Chôken Field 15 (6): 20 (in Japanese).

Miyahara, Y. (1986) An observation on the immigration of the diamondback moth, Plutella xylostella Linne, caused by typhoon. Ann. Rept. Plant Prot. North Japan 37: 143-146 (in Japanese).

Miyahira, M. (1999) 1998 nen Nippon no Tenkou Taifuu (Weather and typhoon of Japan in 1998). Kisho 43 (1): 12-15 (in Japanese).

Morishita, M. and K. Azuma (1990) Use of row cover to protect cabbage from diamondback moth, Plutella $x y$ lostella L. Proc. Kansai Pl. Prot. 32: 29-34 (in Japanese with English summary).

Murata, M., T. Etoh, K. Itoyama and S. Tojo (1998) Sudden occurrence of the common cutworm, Spodoptera litura (Lepidoptera: Noctuidae) in southern Japan during the typhoon season. Appl. Entomol. Zool. 33 (3): 419-427.

Nakajima, S. (1999) Butterflies collected on Yaeyama Islands. Chôken Field 14 (7): 26 (in Japanese).

Nakanishi, M. (2002) Polygonia c-aureum on Yonaguni-jima Island. Chôken Field 17 (4): 28 (in Japanese).

Nishiguchi T. (1999) Collection records of immigrant butterflies on Yonaguni-jima Island in autumn. Chôken Field 14 (3): 30 (in Japanese).

Okinawa Meteorological Station (1998) Extraordinary Weather Report in Okinawa Area. 26. 48 pp. (in Japanese).

Okinawa Meteorological Station (1999) Extraordinary Weather Report in Okinawa Area. 27. 57 pp. (in Japanese).

Okinawa Meteorological Station (2000) Extraordinary Weather Report in Okinawa Area. 28. 49 pp. (in Japanese).

Okinawa Meteorological Station (2001) Extraordinary Weather Report in Okinawa Area. 29. 59 pp. (in Japanese).

Okinawa Meteorological Station (2002) Extraordinary Weather Report in Okinawa Area. 30. 58 pp. (in Japanese).

Shaw, M. W. (1960) The diamond-back moth Plutella maculipennis (Curtis). Trans. Roy. Highland Agr. Soc. Scot. 
6 (4): 56-80.

Shaw, M. W. (1962) The diamond-back moth migration of 1958. Weather 17: 221-234.

Shaw, M. W. and G. W. Hurst (1969) A minor immigration of the diamond-back moth Plutella xylostella (L.) (maculipenis Curtis). Agr. Meteorol. 6: 125-132.

Takahashi, H. (1999) Collection records of immigrant butterflies on Iriomote-jima Island including Polygonia c-aureum in October 1998. Chôken Field 14 (3): 29-30 (in Japanese).

Takegami, A. (2002) Butterflies collected in Yaeyama from summer to winter of 2001. Chôken Field 17 (2): 7-9 (in Japanese).

Takeuchi, T. (1999) Collection records in Yaeyama in 1998.
Chôken Field 14 (7): 27 (in Japanese).

Uehara, K. (1999) Collection records of immigrant butterflies in Yaeyama area in autumn 1998. Chôken Field 14 (2): 28-29 (in Japanese).

Umeda, Y. and I. Awoki (1999) Collection records of immigrant butterflies on Ishigaki-jima and Iriomote-jima Islands in 1998. Chôken Field 14 (10): 30-31 (in Japanese).

Walker, E. H. (1976) Flora of Okinawa and the Southern Ryukyu Islands. Smithonian Institution Press, Washington D. C. $1,159 \mathrm{pp}$.

Yamada, M. (2002) Immigrated butterflies on Ishigaki-jima Island from August 2001 to January 2002. Chôken Field 17 (5): 26-27 (in Japanese). 